\title{
Research Paper: Autobiographical Memory and Interpersonal Problem Solving in Iranian Patients With crossnark Borderline Personality Disorder
}

\author{
Ashraf Akbari Dehaghi', Shima Tamannaeifar ${ }^{2 *}$, Aliasghar Asgharnejad Farid ${ }^{3}$ \\ 1. Department of Clinical Psychology, University of Social Welfare and Rehabilitation Sciences, Tehran, Iran. \\ 2. Department of Clinical Psychology, Roozbeh Psychiatric Hospital, Tehran University of Medical Sciences, Tehran, Iran. \\ 3. Tehran Psychiatric Institute, Iran University of Medical Sciences, Tehran, Iran.
}

Article info:

Received: 14 Nov. 2016

Accepted: 10 Feb. 2017

Keywords:

Borderline personality disorder, Autobiographical memory, Interpersonal problem solving, Women
Crtation: Akbari Dehaghi, A., Tamannaeifar, Sh., \& Asgharnejad Farid, A. (2017). Autobiographical Memory and Interpersonal Problem Solving in Iranian Patients With Borderline Personality Disorder. Journal of Practice in Clinical Psychology, 5(2), 99-106. https://doi.org/10.18869/acadpub.jpcp.5.2.99

https://doi.org/10.18869/acadpub.jpcp.5.2.99

\section{Introduction}

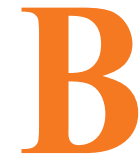

orderline Personality Disorder (BPD) is characterized by a widespread instability pattern in interpersonal relationships, emotion, self-image, and impulsivity (Bray, Barrowclough, \& Lobban, 2007).

Generally, the individuals suffering from emotional disorders tend to recall overgeneral autobiographical memories compared to those without emotional disorders (Valentino, 2011). Autobiographical memory, a kind of memory associated with recalling past events, is important to pursue goals by remembering previous problem solving methods (Conway \& Pleydell-Pearce, 2000; Williams et al., 2007). According to Conway's cognitive model, the autobiographical memory (Conway and Pleydell-Pearce, 2000) is hierarchically structured so that general information sits on top and specific information on lower levels.

* Corresponding Author:

Shima Tamannaeifar, PhD

Address: Department of Clinical Psychology, Roozbeh Psychiatric Hospital, Tehran University of Medical Sciences, Tehran, Iran.

Tel: +98 (912) 7644113

E-mail: sh-tamannaeifar@farabi.tums.ac.ir 
Williams (1996) reported that depressed patients retrieve fewer specific memories than control group, displaying an "overgeneral retrieval" style. Additionally, depressed patients need more time to recall memories than the control group. Also, patients with Post-Traumatic Stress Disorder (PTSD) have difficulty in recalling specific memories (McNally, Lasko, Macklin, \& Pitman 1995). Since depression and PTSD have high comorbidity with BPD (Zanarini et al., 1998) and one of the diagnostic criteria for BPD is suicidal behavior, these findings are particularly relevant to the examination of autobiographical memory in patients with BPD (Renneberg, Theobald, Nobs, \& Weisbrod, 2005). A meta-analysis by Sumner, Griffith, and Mincka (2010) showed reliable relationship between overgeneral memory and depression so that higher levels of overgeneral memory predict more severe depressive symptoms. Similar findings have been reported in adult community sample (Van Daele, Griffith, Van den Bergh, \& Hermans, 2014), students (Boelen, Huntjens, \& Van den Hont, 2013), and adolescents (Hipwell, Sapotichne, Klostermann, Battista, \& Keenan, 2011).

Comparison of retrieval ability between patients with BPD and depression showed that patients with BPD recall specific negative memories easily and relatively fast. They do not uncover 'mnemonic interlock' like depressive patients, which is unlikely to protect against emotional disturbances (Barnhofer, Jong-Meyer, Kleinpaß, \& Nikesch 2002). A study on responding to Autobiographical Memory Test (AMT) (Williams \& Broadbent, 1986) examined a sample of 30 female inpatients with BPD with a group of 27 depressed inpatients and a non-clinical group of 30 women. Specific memories in depressed patients were fewer than the control group. They reported more categorical memories than the other groups and needed longer time for recalling. Patients with BPD neither differ from the normal group regarding specificity, nor latency of retrieved memories (Renneberg et al., 2005).

The overgenerality in autobiographical memory has been found to correlate with problem-solving performance (Pollock \& Williams, 2001) and the prediction of the depression persistence (Dalgleish, Spinks, Yiend, \& Kuyken, 2001).

Interventions such as dialectical behavior therapy for patients with BPD often include problem-solving therapy elements. Kehrer and Linehan (1996) found that incompatible problem solving in patients with BPD was a significant predictor of foregoing suicidal behaviors. Evans, Williams, O'Loughlin, \& Howells (1992) have shown that when specific memories of copping with past situations are not easily accessible, copping with present problems is not possible. Bray et al. ( 2007) reported that the patients with BPD exhibit deficits in their social problem solving abilities. However the majority of these deficits are not specific to the BPD group and also found in the clinical group, indicating that a common factor, such as a negative effect, may account for observed deficits. Specific problem solving deficits identified in the BPD group were as follows: determining more general solutions, having negative problem orientation, and impulsive/carelessness attitude toward problem solving on means-ends problemsolving procedure. Another study (Kremers, Spinhoven, Van der Does, \& Van Dyck, 2006) investigated problem solving and autobiographical memory in 78 outpatients with BPD and a control group of 44 patients of BPD who had diagnosis of major depressive disorder. The results showed that patients with BPD had more difficulties in problem solving. No significant correlation was reported between problem solving and autobiographical memory.

Although some studies investigated autobiographical memory and problem solving in clinical samples such as patients with major depressive disorder (MDD) or PTSD, no study has directly examined the relation-ship between them in patients with BPD. The aim of the present study was to investigate problem solving capabilities as well as the specificity of autobiographical memory in patients with BPD and control groups.

\section{Methods}

The study participants comprised 15 female patients with BPD and 15 control females matched for age, education, and marital status. This was a cross-sectional study and study samples were selected by conven-ience sampling method because of accessibility and closeness to researcher. Diagnosis of BPD was verified with a psychiatrist based on the semi-structured clinical interview of DSM-IV, Axis II (SCID-II) for personality disorders (First, Spitzer, Gibbon, \& Williams, 1995; Sharifi et al., 2007). The exclusion criteria were having comorbidity disorders such as major depressive disorder, schizophrenia, obsession-compulsion, or bipolar disorder. They were also screened against conspicuous brain lesions, Electroconvulsive Therapy (ECT) in the recent six months, and even substance abuse.

More than half of the patients had committed suicide or threatened to do so in the past as patients were selected from Hazrat-e-Rasool Hospital which is a general hospital with a psychiatry ward. The clinical sample included 5 outpatients and 10 inpatients.

Healthy participants, mostly hospital staff, were selected by convenience sampling method and screened by 
inclusion and exclusion criteria. They had no psychiatric criteria based on SCID-I and matched for age, education, and marital status with the BPD group.

The structured clinical interview for DSM-IV Axis II (SCID-II): The SCID-II (First et al., 1995) is a semi-structured diagnostic interview that assesses personality disorders described in DSM-IV. Each participant completed the SCID-II personality questionnaire to identify potential personality disorders and then the diagnosis was confirmed using the SCID-II interview. The SCID-II is commonly used in clinical situations and have acceptable psychometric characteristics (Maffei et al., 1997). Bakhtiari (2000) estimated the content validity and test-retest reliability $(r=0.86)$ of the SCID in an Iranian population.

Means-Ends Problem Solving Task (MEPS): Based on problem-solving task presented by Platt, Spivack, and Bloom (1975), a similar and culturally modified task five situation was developed in another study (Kaviani et al., 2005). This task was used in the present study to measure different aspects of problem-solving in the target population. Each situation involved a stated and desired end. The participant was requested to complete the middle part of the story so that the protagonist would achieve the desired outcome. In the present study, a number of appropriate components for the study objectives were scored as follows: latency to response onset (first word of response), the number of means (including appropriate and inappropriate means), relevancy ratio (appropriate means/number of means), and means effectiveness. The effectiveness rating was determined using the criteria of Evans and Williams et al. (1992). To determine the effectiveness, the two independent raters (one unaware of the participants) rated 3 -point scale $(0=$ not at all effective; $1=$ effective; $2=$ very effective). This procedure submitted a desirable inter-rated agreement. Mean rater scores were used in the analysis. The validity and reliability of the Persian version of MEPS has been piloted by Kaviani et al. (2005).

Autobiographical Memory Test (AMT): The Autobiographical Memory Test (AMT) (Williams \& Broadbent, 1986) assesses the ability to recall specific autobiographical memory comprises 5 pleasant, 5 unpleasant, and 5 neutral adjectives as cue words. Each participant was asked to recall a specific memory in response to the presented cue words, occurring anytime in their lives before the last week. If the subject did not response to the cue words within limited time, a 60-second time was considered as the latency. The cue words have been proved to possess some specific capacities (Kaviani, RahimiDarabad, \& Naghavi, 2005). The researcher and a blind rater used an 11-point scale (from $0=$ very overgeneral to
$10=$ very specific) to rate specificity to overgenerality. The correlation of ratings between the two judges were highly significant $(\mathrm{r}=0.79, \mathrm{P}<0.01)$. The final scores used in data analysis were the experimenters' rating. The patients referred to study by their psychiatrists were interviewed and screened on the basis of the inclusion and exclu-sion criteria. The written informed consent forms were signed by subjects who were assured of keeping their personal information confidential and asked to answer the tests. The procedure of assessment took 25-40 min.

\section{Results}

\section{Problem solving deficits in patients with BPD and control group}

Participants comprised 15 female patients with BPD (mean age $=23.13 \mathrm{y}$ ) and 15 healthy females (mean age $=27.65 \mathrm{y})$, that matched for age $( \pm 5$ years $)$, education, and marital status. This was a cross-sectional study. Demographic characteristics of BPD patients and healthy group have been represented in Table 1.

In general, the interviews using SCID-II showed that the participants with BPD had deficits in the following dimensions: frantic efforts to avoid abandonment $(66 \%)$, a pattern of disturbed interpersonal relation-ship (92\%), identity disturbance (83\%), impulsivity (50\%), recurrent suicide or suicide threats $(75 \%)$, affective instability $(66 \%)$, feeling of emptiness $(100 \%)$, intense anger $(66 \%)$, and paranoid ideation $(58 \%)$. A series of $t$ tests was performed to compare group performance on different variables measured in the problem-solving task. Table 2 presents statistics of problem-solving measures in both BPD and control groups. The findings show that, compared with the control group, the BPD group provided less effective strategies ( $\mathrm{t}=4.47, \mathrm{P}<0.001$ ); another finding shows that people with BPD provide a fewer number of problem-solving means $(\mathrm{t}=3.43, \mathrm{P}<0.001)$. In addition, the patients with BPD use more irrelevant means. The study findings show significant differences between two groups. Such data are presented in Table $2(\mathrm{t}=3.91, \mathrm{P}<0.001)$. The next finding were that the participants with BPD took longer to respond to the task, compared to the performance of healthy control group $(\mathrm{t}=2.29, \mathrm{P}<0.05)$. Moreover, Table 2 presents a lower relevancy ratio in the people with $\mathrm{BPD}$ compared to healthy control group $(\mathrm{t}=4.10, \mathrm{P}<0.001)$.

\section{General retrieval of autobiographical memory in patients with BPD and controls}

The results of autobiographical memory in two groups (Table 3) show that latency period of patients with BPD 
Table 1. Demographic variables of patients with BPD and healthy group $(n=30)$

\begin{tabular}{|c|c|c|c|c|c|}
\hline \multirow{2}{*}{$\begin{array}{c}\text { Group } \\
\text { Variable }\end{array}$} & \multicolumn{2}{|l|}{ Patients } & \multicolumn{3}{|c|}{ Healthy } \\
\hline & Variable Levels & No. & $\%$ & No. & $\%$ \\
\hline \multirow{4}{*}{ Age, $y$} & $18-20$ & 2 & 13.3 & 6 & 40 \\
\hline & $21-25$ & 12 & 80 & 7 & 46.7 \\
\hline & & & & 1 & 67 \\
\hline & $31-35$ & 1 & 68 & 1 & 67 \\
\hline \multirow{3}{*}{ Job } & Employed & 5 & 33.3 & 3 & 20 \\
\hline & Unemployed & 9 & 60 & 10 & 66.7 \\
\hline & Student & 1 & 6.7 & 2 & 13.3 \\
\hline \multirow{2}{*}{ Marital status } & Single & 13 & 86.7 & 14 & 93.3 \\
\hline & Married & 2 & 13.3 & 1 & 6.7 \\
\hline \multirow{4}{*}{ Education } & High school graduated & 2 & 13.3 & 1 & 6.7 \\
\hline & Diploma & 9 & 60 & 10 & 66.7 \\
\hline & Bachelor & 3 & 20 & 3 & 20 \\
\hline & Master & 1 & 6.7 & 1 & 6.7 \\
\hline
\end{tabular}

in response to pleasant words is longer than the controls. However, the difference between BPD and the control group regarding latency was insignificant. On the other hand, the patients with BPD got lower specificity scores in their personal memories in response to pleasant, neutral $(\mathrm{P}<0.05)$, and unpleasant $(\mathrm{P}<0.01)$ cues. Total number of words in response to autobiographical memory had significant differences as well, and participants in the control group expressed more words in ATM than the BPD group. To detect the associations between autobiographical memory and problem solving, the Pearson correlation method was conducted for each group results. Table 4 presents the correlation between speci- ficity and problem solving in two groups. Only, two significant correlations were observed: relevancy ratio was positively correlated with latency for pleasant and neutral words in the control group.

\section{Discussion}

The present study showed that patients with BPD reported fewer effective solutions than the controls. This finding is in line with Bray et al. (2007) studies who found difficulties in problem solving in the clinical group such as patients with BPD. Hence the patients with BPD either do not have necessary skills to solve their problems, or they

Table 2. Statistics on problem-solving measures

\begin{tabular}{cccc}
\hline \multicolumn{3}{c}{ Group } \\
\hline Measure & BPD $(\mathbf{n}=\mathbf{1 5}), \mathbf{M}(\mathbf{S D})$ & Control $(\mathbf{n}=\mathbf{1 5}), \mathbf{M}(\mathbf{S D})$ & $\mathbf{t}$ \\
\hline Number of means & $4.73(1.94)$ & $8.00(3.21)$ & $3.43^{* *}$ \\
\hline Number of irrelevant means & $2.00(1.81)$ & $0.13(0.35)$ & $3.91^{* *}$ \\
\hline Relevancy ratio & $2.36(1.00)$ & $3.88(1.01)$ & $4.10^{* *}$ \\
Effectiveness & $3.06(1.53)$ & $7.13(2.16)$ & $4.4^{* *}$ \\
\hline Latency & $45.26(34.67)$ & $20.33(23.87)$ & $2.29^{*}$ \\
\hline
\end{tabular}

$* \mathrm{P}<0.05$ ** $\mathrm{P}<0.001$

PRACTICE in
CLINICAL PSYCH $\oplus$ LOGY 
Table 3. Statistics on Autobiographical Memory Test in patients with BPD and controls

\begin{tabular}{|c|c|c|c|c|c|}
\hline & & Controls ( $n=15$ ) & BPD $(n=15)$ & \multirow{2}{*}{$\mathbf{t}$} & \multirow{2}{*}{ P-value } \\
\hline & & $M(S D)$ & $M(S D)$ & & \\
\hline & Pleasant & 49.93(36.33) & $37.60(21.48)$ & -1.13 & NS \\
\hline \multirow[t]{3}{*}{ Latency } & Unpleasant & $50.43(45.72)$ & 29.33(14.64) & -1.70 & NS \\
\hline & Neutral & $52.1(29.4)$ & 47.96(33.65) & -0.35 & NS \\
\hline & Pleasant & $87.83(56.18)$ & 44.66(39.93) & -1.89 & 0.05 \\
\hline \multirow[t]{3}{*}{ Specificity } & Unpleasant & 79.40(46.96) & 35.93(39.99) & -2.73 & 0.01 \\
\hline & Neutral & $69.33(62.08)$ & $29(30.93)$ & -2.25 & 0.05 \\
\hline & Pleasant & $134.27(75.34)$ & $75.46(42.09)$ & -2.63 & 0.005 \\
\hline \multirow[t]{2}{*}{ Number of words } & Unpleasant & 118.4(77.22) & $88.33(49.91)$ & -2.05 & 0.05 \\
\hline & Neutral & 138.13(88.27) & 79.93(61.27) & -1.51 & 0.05 \\
\hline
\end{tabular}

Table 4. Correlation matrix of specificity and problem solving in patients with BPD and control groups

\begin{tabular}{|c|c|c|c|c|c|}
\hline & & & Relevant Solution & The Ratio of Relevancy & Effectiveness of Responses \\
\hline \multirow{9}{*}{ BPD } & \multirow{3}{*}{ Latency } & Pleasant & 0.15 & -0.03 & 0.03 \\
\hline & & Unpleasant & -0.21 & 0.31 & -0.37 \\
\hline & & Neutral & 0.38 & 0.004 & 0.35 \\
\hline & \multirow{3}{*}{ Total words } & Pleasant & 0.39 & -0.35 & 0.24 \\
\hline & & Unpleasant & 0.09 & -0.11 & 0.12 \\
\hline & & Neutral & 0.004 & 0.25 & 0.13 \\
\hline & \multirow{3}{*}{ Specificity } & Pleasant & -0.19 & -0.06 & -0.2 \\
\hline & & Unpleasant & 0.005 & -0.17 & -0.12 \\
\hline & & Neutral & 0.16 & -0.19 & 0.09 \\
\hline \multirow{9}{*}{ Control } & \multirow{3}{*}{ Latency } & Pleasant & -0.47 & $0.59 *$ & -0.51 \\
\hline & & Unpleasant & -0.19 & 0.49 & -0.3 \\
\hline & & Neutral & -0.37 & $0.52^{*}$ & -0.42 \\
\hline & \multirow{3}{*}{ Total words } & Pleasant & -0.05 & 0.51 & -0.08 \\
\hline & & Unpleasant & 0.02 & 0.3 & 0.006 \\
\hline & & Neutral & -0.05 & 0.45 & -0.007 \\
\hline & \multirow{3}{*}{ Specificity } & Pleasant & 0.1 & -0.14 & 0.02 \\
\hline & & Unpleasant & 0.09 & -0.09 & 0.11 \\
\hline & & Neutral & 0.14 & -0.06 & 0.14 \\
\hline
\end{tabular}


are in such an emotional state that it is difficult to apply the skills. One the basic components of BPD is to teach problem solving (Linehan, 1993a). Another finding was that the latency period of problem-solving in patients with BPD is longer than the controls i.e., patients with BPD take more time to retrieve information and find the solutions. Kehrer and Linehan (1996) also noted that incompatible problem solving is an important factor for suicidal behavior. Some studies asserted that people need to retrieve the information of past solutions to pursue their goals (Conway \& Pleydell-Pearce, 2000; Williams et al., 2007).

Another finding was that an overgeneral tendency was found in patients with BPD to retrieve the memories compared to the control group. This finding is supported by the fact that PTSD and depression, which have high comorbidity with BPD, display overgeneral memory style (Williams, 1996; McNally et al., 1995; Zanarini et al., 1998; Renneberg et al., 2005; Valentino 2011). Cognitive models of PTSD suggest that our overgeneral memory for traumatic events may limit ability of the patient to integrate the traumatic memories with other autobiographical memory and one's self-concept (Dalgleish, 2004). And intrusions of memories in a long period of time absorb the resources that could be used for effortful memory research (Wessel, Merckelbach, \& Dekkers, 2002). Williams (1996) proposed that overgeneral memory helps patients block emotional events with negative effects (Geraerts, Dritschel, Kreplin, Miyagawa, \& Waddington 2012). It is possible that low memory specificity has adaptive function by restricting the availability of negative effects that have related to specific memories (Williams et al., 2007). Future mood disturbance could be decreased by improving specific memories in patients at risk. When depressed patients were trained to become more specific, depressive symptoms, and ruminative levels were found to mitigate (Neshat-Doost et al., 2013; Williams, 2007). According to the functional avoidance hypothe-sis (Williams et al., 2007), an overgeneral retrieval style preserves the one's self-concept, because important unpleasant events and associated emotions are not activated. This strategy can prevent the development of new depressive episodes in short term, but it may improve post-traumatic symptom or mood disorder in long term, because overgeneral memory decreases the efficacy of social problem solving (Boelen et al., 2013).

Although some researchers reported positive correlations between autobiographical memory specificity and problem solving relevancy ratio (Pollock \& Williams 2001), no significant correlation appeared in our findings. Thus, claiming underling effect of autobiographical memory on social problem solving is not supported. Perhaps, social problem solving difficulties are influenced by other factors like emotion dysreg-ulation rather than specificity of memories (Kremers et al., 2006). The result of this study must be considered with regard to some limitations.

First, patients with BPD form a very heterogeneous group. Some patients display impulsivity, while others are more introverted and extremely insecure (Renneberg et al., 2005), that can explain no significant correlation between problem solving and specific memories. In addition, we were unable to identify homogenous patterns. This remains a task for future studies with larger sample sizes. Another limita-tion of this study was the exclusion of male patients that limit the study generalization. Also, limited number of patients with BPD who do not suffer any other disorders according to DSM-IV-TR in Axis I, was another study limitation.

\section{Acknowledgments}

The authors would like to acknowledge the assistance of Hazrat Rasool Hospital staff. This research did not receive any specific grant from funding agencies in the public, commercial, or not-for-profit sectors.

\section{Conflict of Interest}

The authors declared no conflicts of interest.

\section{References}

Bakhtiari, M. (2000). [The study in psychiatric disorder in patients with body dysmorphic disorder (Persian)] [MSc. thesis]. Tehran: Iran University of Medical Sciences.

Barnhofer, T., Jong-Meyer, R., Kleinpaß, A., \& Nikesch, S. (2002). Specificity of autobiographical memories in depression: An analysis of retrieval processes in a think-aloud task. British Journal of Clinical Psychology, 41(4), 411-416. doi: 10.1348/014466502760387524

Boelen, P. A., Huntjens, R. J. C., \& van den Hout, M. A. (2013). Concurrent and prospective associations of habitual overgeneral memory and prospection with symptoms of depression, general anxiety, obsessive compulsiveness, and post-traumatic stress. Memory, 22(7), 747-758. doi: 10.1080/09658211.2013.824985

Bray, S., Barrowclough, C., \& Lobban, F. (2007). The social problem-solving abilities of people with borderline personality disorder. Behaviour Research and Therapy, 45(6), 1409-1417. doi 10.1016/j.brat.2006.06.011

Conway, M. A., \& Pleydell-Pearce, C. W. (2000). The construction of autobiographical memories in the self-memory system. Psychological Review, 107(2), 261-288. doi: 10.1037/0033295x.107.2.261 
Dalgleish, T., Spinks, H., Yiend, J., \& Kuyken, W. (2001). Autobiographical memory style in seasonal affective disorder and its relationship to future symptom remission. Journal of Abnormal Psychology, 110(2), 335-340. doi: 10.1037/0021-843x.110.2.335

Dalgleish, T. (2004). Cognitive approaches to posttraumatic stress disorder: The evolution of multirepresentational theorizing. Psychological Bulletin, 130(2), 228-260. doi: 10.1037/0033-2909.130.2.228

Evans, J., Williams, J. M. G., O'Loughlin, S., \& Howells, K. (1992). Autobiographical memory and problem-solving strategies of parasuicide patients. Psychological Medicine, 22(02), 399. doi: $10.1017 / \mathrm{s} 0033291700030348$

First, M. B., Spitzer, R. L., Gibbon, M., \& Williams, J. B. W. (1995) The structured clinical interview for DSM-III-R personality disorders (SCID-II). Part I: Description. Journal of Personality Disorders, 9(2), 83-91. doi: 10.1521/pedi.1995.9.2.83

Geraerts, E., Dritschel, B., Kreplin, U., Miyagawa, L., \& Waddington, J. (2012). Reduced specificity of negative autobiographical memories in repressive coping. Journal of Behavior Therapy and Experimental Psychiatry, 43, S32-S36. doi: 10.1016/j.jbtep.2011.05.007

Hipwell, A. E., Sapotichne, B., Klostermann, S., Battista, D., \& Keenan, K. (2011). Autobiographical memory as a predictor of depression vulnerability in girls. Journal of Clinical Child \& Adolescent Psychology, 40(2), 254-265. doi: 10.1080/15374416.2011.546037

Kaviani, H., Rahimi-Darabad, P., \& Naghavi, H. R. (2005). Autobiographical memory retrieval and problem-solving deficits of iranian depressed patients attempting suicide. Journal of Psychopathology and Behavioral Assessment, 27(1), 39-44. doi: $10.1007 /$ s10862-005-3264-0

Kehrer, C. A., \& Linehan, M. M. (1996). Interpersonal andemotional problem solving skills and parasuicide among women with borderline personality disorder. Journal of Personality Disorders, 10(2), 153-163. doi: 10.1521/ pedi.1996.10.2.153

Kremers, I. P., Spinhoven, P., Van der Does, A. J. W., \& Van Dyck, R. (2006). Social problem solving, autobiographical memory and future specificity in outpatients with borderline personality disorder. Clinical Psychology \& Psychotherapy, 13(2), 131-137. doi: 10.1002/cpp.484

Linehan, M. M. (1993a). Cognitive-behavioral treatment of borderline personality disorder. New York: Guilford Press.

Maffei, C., Fossati, A., Agostoni, I., Barraco, A., Bagnato, M., Deborah, D., et al. (1997). Interrater reliability and internal consistency of the structured clinical interview for DSM-IV axis II personality disorders (SCID-II), version 2.0. Journal of Personality Disorders, 11(3), 279-284. doi: 10.1521/pedi.1997.11.3.279

McNally, R. J., Lasko, N. B., Macklin, M. L., \& Pitman, R. K. (1995). Autobiographical memory disturbance in combatrelated posttraumatic stress disorder. Behaviour Research and Therapy, 33(6), 619-630. doi: 10.1016/0005-7967(95)00007-k

Neshat-Doost, H. T., Dalgleish, T., Yule, W., Kalantari, M., Ahmadi, S. J., Dyregrov, A., et al. (2013). Enhancing autobiographical memory specificity through cognitive training. Clinical Psychological Science, 1(1), 84-92. doi: 10.1177/2167702612454613

Platt, J. J., Spivack, G., Bloom, W. (1975). Manual for the meansends problem-solving procedure (MEPS): A measure of interper- sonal cognitive problem-solving skill. Philadelphia: Hahnemann Medical college and Hospital.

Pollock, L. R., \& Williams, J. M. G. (2001). Effective problem solving in suicide attempters depends on specific autobiographical recall. Suicide and Life-Threatening Behavior, 31(4), 386-396. doi: 10.1521/suli.31.4.386.22041

Rase F., Williams J. M. G., \& Hermans D.(2009) On the test-retest reliability of the autobiographical memory test. In L. B. Palcroft, \& M. V. Lopez (Eds.), Personality Assessment: New Research (pp. 391-397). New York: Nova Science.

Renneberg, B., Theobald, E., Nobs, M. \& Weisbrod, M. (2005). Autobiographical memory in borderline personality disorder and depression. Cognitive Therapy and Research 29(3): 343-358. doi: 10.1007/s10608-005-4267-4

Sharifi, V., Assadi, S. M., Mohammadi, M. R., Amini, H., Kaviani, H., Semnani, Y., et al. (2007). Structured clinical interview for DSM-IV (SCID): Persian translation and cultural adaptation. Iranian Journal of Psychiatry, 2(1), 46-48.

Sumner, J. A., Griffith, J. W., \& Mineka, S. (2010). Overgeneral autobiographical memory as a predictor of the course of depression: A meta-analysis. Behaviour Research and Therapy, 48(7), 614-625. doi: 10.1016/j.brat.2010.03.013

Valentino, K. (2011). A developmental psychopathology model of overgeneral autobiographical memory. Developmental Review, 31(1), 32-54. doi: 10.1016/j.dr.2011.05.001

Van Daele, T., Griffith, J. W., Van den Bergh, O., \& Hermans, D. (2014). Overgeneral autobiographical memory predicts changes in depression in a community sample. Cognition and Emotion, 28(7), 1303-1312. doi: 10.1080/02699931.2013.879052

Wessel, I., Merckelbach, H., \& Dekkers, T. (2002). Autobiographical memory specificity, intrusive memory, and general memory skills in Dutch-Indonesian survivors of the World War II Era. Journal of Traumatic Stress, 15(3), 227-234. doi 10.1023/a:1015207428675

Williams J. M. G. (1996). Depression and the specificity of autobiographical memory. In D. C. Rubin (Ed.), Remembering Our Past: Studies in Autobiographical Memory (pp. 244-267). Cambridge: Cambridge University Press.

Williams, J. M., \& Broadbent, K. (1986). Autobiographica memory in suicide attempters. Journal of Abnormal Psychology, 95(2), 144-149. doi: 10.1037/0021-843x.95.2.144

Williams, J. M. G., Barnhofer, T., Crane, C., Herman, D., Raes, F., Watkins, E., et al. (2007). Autobiographical memory specificity and emotional disorder. Psychological Bulletin, 133(1), 122-148. doi: 10.1037/0033-2909.133.1.122

Zanarini, M. C., Frankenburg, F. R., Dubo, E. D., Sickel, A. E. Trikha, A., Levin, A., et al. (1998). Axis I comorbidity of borderline personality disorder. American Journal of Psychiatry, 155(12), 1733-1739. doi: 10.1176/ajp.155.12.1733 
